Introdução

Segundo os Parâmetros Curriculares Nacionais (BRASIL, 1988), até o ano de 1961 as aulas de ciências eram ministradas apenas para o antigo ginásio e durante um longo período a educação foi regida exclusivamente pelo método tradicional, onde o professor atuava como um transmissor de conhecimento acumulado.

A partir de então (e nos últimos anos) os objetivos ligados a educação científica foram constantemente adequados à medida em que a ciência foi reconhecida como fundamental para o desenvolvimento social, econômico e cultural da sociedade. Assim, o ensino de ciências ganhou devida importância, sendo capaz de elucidar os impactos dos movimentos em prol da reforma educacional (KRASILCHIK, 2011).

Atualmente, muitos estudos têm apresentado propostas metodológicas para o processo de ensino-aprendizagem, incluindo o uso de recursos alternativos e modalidades didáticas variadas para o ensino de ciências, considerando a interação existente entre aluno-professorconhecimento (BRASIL, 1988). Krasilchik (2011) propõe a utilização de aulas práticas, demonstrações, exposições, simulações, discussões, etc., salientando a importância do professor na definição do que é, de fato, conveniente para a classe a qual a atividade se destina, o tempo, o conteúdo propostos, os valores e convicções do docente.

Porém, o antigo método tradicional ainda é frequente na educação básica, onde é adotada pelos professores a concepção de aprendizagem como transmissão e, para os alunos, a de ciência como um agente imutável e inquestionável (SCHNETZLER, 1992). Assim, pouco se faz uso de recursos didáticos alternativos e lúdicos para o processo formativo do estudante.

Os recursos didáticos são aqueles que facilitam a interação existente entre o professor com seus alunos e dos alunos com o conhecimento (CÂNDIDO et al., 2012) e por isso é essencial que o docente utilize métodos variados no ensino, deste modo, exercitando habilidades variadas e estimulando a aprendizagem. Para Cunha (1998), o emprego do lúdico na prática pedagógica é caracterizado por duas funções: prazer e esforço, além de integrar outras dimensões, como afetividade e trabalho em equipe.

O jogo didático, por exemplo, que é o objeto de estudo desse trabalho, é definido por Huizinga (1996, p. 44) como "[...] uma atividade voluntária, que ocorre em um espaço definido e com um tempo determinado" e raramente é utilizado pelos professores de ciências naturais, mesmo se tratando de uma ferramenta pedagógica relevante, pois permite o desenvolvimento: 


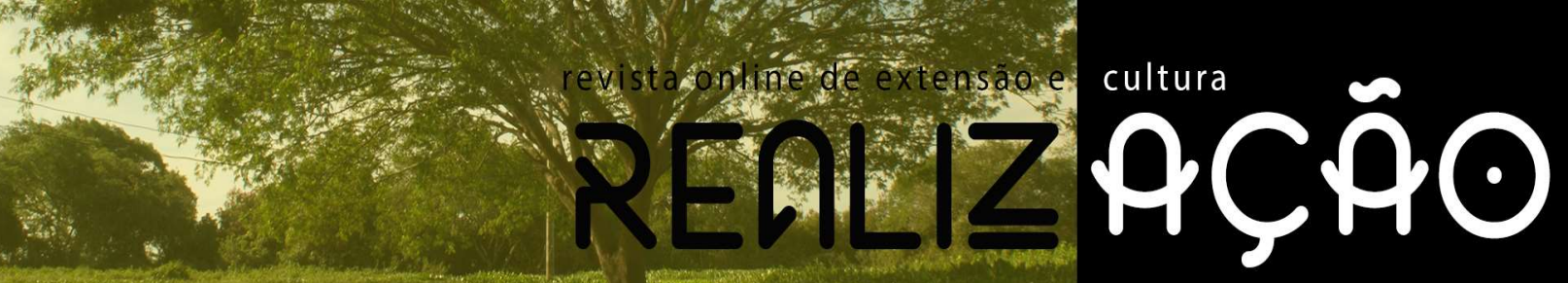

[...]de competências no âmbito da comunicação, das relações interpessoais, da liderança e do trabalho em equipe, utilizando a relação entre cooperação e competição em um contexto formativo. O jogo oferece o estímulo e o ambiente propícios que favorecem o desenvolvimento espontâneo e criativo dos alunos e permite ao professor ampliar seu conhecimento de técnicas ativas de ensino, desenvolver capacidades pessoais e profissionais para estimular nos alunos a capacidade de comunicação e expressão, mostrandolhes uma nova maneira, lúdica, prazerosa e participativa de relacionar-se com o conteúdo escolar, levando a uma maior apropriação dos conhecimentos envolvidos (BRASIL, 2006, p. 28).

Segundo Kishimoto (2004) os jogos são derivados de práticas e fragmentos culturais, tanto que são destacadas evidencias dessas atividades por povos antigos, como os gregos, que já executavam algumas brincadeiras. Para Huizinga (1971), já estão presentes desde os primórdios e constituem a base das civilizações. $O$ autor ainda aponta que nele verificam-se todas as características das atividades lúdicas, como a tensão, o entusiasmo e a solenidade. Fortuna (2003, p. 15) reafirma a utilização do jogo como método que garante o desenvolvimento de diversas habilidades: "a iniciativa, a imaginação, o raciocínio, a memória, a atenção, a curiosidade e o interesse".

Dentre as características citadas do jogo, deve-se mensurar o desenvolvimento social favorecido pela utilização desse recurso no processo de ensino-aprendizagem. Segundo Piaget (1982) os jogos propõe a existência de parceiros, regras e obrigações a serem respeitadas, conferindo-lhe uma função social e o desenvolvimento do pensamento. Freire (1992) discorre sobre a relevância dos jogos para a formação do ser humano. Na perspectiva desses autores, os jogos incitam a interação dos alunos uns com os outros, com os professores e com o conhecimento. Desse modo, contemplam não apenas o desenvolvimento do domínio cognitivo, mas também do domínio afetivo e psicomotor.

Além de promover a socialização entre os alunos e professores, os jogos didáticos são retratados em diversos trabalhos como recursos facilitadores do conhecimento, principalmente por favorecerem a aprendizagem significativa, pautada na teoria de David Ausubel (1968, 1978, 1980).

Segundo Moreira (2014), a aprendizagem significativa ocorre quando o indivíduo é capaz de relacionar uma nova informação com aspectos presentes em sua estrutura cognitiva, ou seja, é um processo que se refere à interação existente entre a nova informação e a informação que já é conhecida pelo aluno. Ausubel define esses conceitos ou proposições presentes na estrutura cognitiva do indivíduo como subsunçores. 

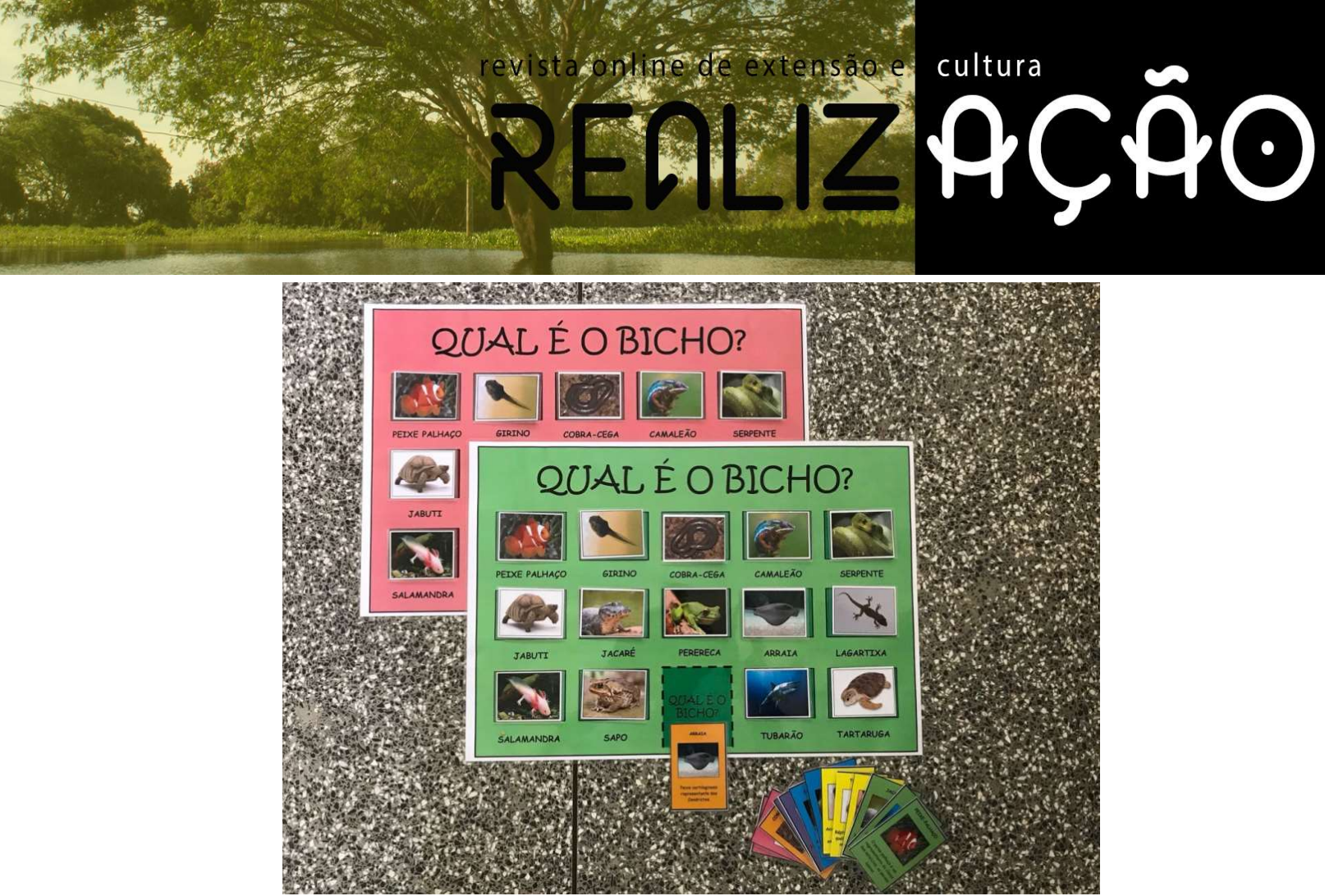

Figura 1 - O jogo "Qual é Bicho?" composto por 2 tabuleiros, 14 pares de cartas figuras e 14 cartas figuras descritivas.

\section{Regras do jogo}

- Cada equipe recebe 14 cartas com imagens dos animais, 1 tabuleiro que possui 14 espaços correspondentes às figuras das cartas, que deverão ser anexadas ao mesmo.

- Ambas terão acesso às cartas figuras descritivas e cada equipe irá escolher apenas 1 destas cartas, a qual deverá ser mantida em sigilo.

- Em seguida, os participantes da equipe adversária tentarão descobrir qual a carta selecionada pelos oponentes por meio de perguntas referentes as características dos animais. As perguntas só podem ser respondidas com sim ou não e por observação das cartas figuras, a equipe adversária mantém ou as retira do tabuleiro conforme a resposta apresentada.

- Vence o jogo a equipe que descobrir primeiro a carta figura escolhida pela equipe oponente e fizer maior número de pontos em partidas consecutivas.

O método avaliativo proposto para o jogo conta com duas partes. A primeira se refere à observação direta dos alunos durante a execução do jogo. Para tanto, um membro do projeto ficou responsável por cada equipe de jogo, avaliando o desempenho comportamento e motivação das equipes durante a atividade.

A segunda parte da avaliação corresponde a aplicação de um questionário contendo cinco questões relacionadas a opinião dos alunos sobre o layout do jogo, dificuldade das perguntas, 
participação e interação dos alunos em suas equipes. Os dados foram quantificados em valores percentuais e os resultados apresentados em gráficos.

\section{Resultados e Discussões}

O total de participantes no jogo foi de quinze alunos, os quais formaram 3 equipes subdivididas em 2 grupos. Após as equipes organizadas, sugeriu-se que lessem as regras antes de iniciar a partida. A utilização das regras tem direta associação com o que é postulado por Bloom (1964) e Freire (1992) com relação à contemplação do domínio afetivo. Este se refere ao desenvolvimento dos valores, do respeito ao momento do colega, sua opinião, seu espaço e ao que é estabelecido igualitariamente como norma aos participantes.

Os alunos buscaram seguir as regras estabelecidas, sendo que, conforme havia desrespeito a elas, alguns participantes eram sinalizados por seus colegas a fim de se estabelecer as mesmas condições de jogo para todos.

Os estudantes se mantiveram estimulados e participativos durante as partidas, demonstrando interesse pelo material. E considerando a ampla gama de conceitos e teorias que envolvem o extenso conteúdo de vertebrados, o uso deste recurso tornou prazerosa sua aprendizagem. O modelo tradicional de ensino pode o tornar "chato" e "cansativo" segundo relatos dos próprios alunos em atividades lúdicas similares no processo ensino-aprendizagem das ciências, conforme citado por Metrau e Barreto (2007).

No decorrer da partida, um dos alunos comentou que gostaria de levar o jogo para que pudesse jogar com sua família. Os demais alunos também estavam motivados, interagindo com a equipe a fim de formular boas perguntas para eliminar o maior número possível de cartas figuras do tabuleiro e obterem vantagem no jogo.

Após finalizada a primeira partida as equipes pediram para jogar novamente e a mesma se repetiu por 3 a 4 vezes, totalizando ao redor de 1 hora de atividade lúdica. Ficou evidente a cada nova partida, a exploração aos detalhes das figuras do tabuleiro e a formulação de questões mais elaboradas e coerentes, revelando uma interessante atividade de aprendizagem.

As questões elaboradas pelos alunos faziam menção a morfologia, hábitos de vida (locomoção, alimentação), coloração dos animais ou mesmo o grupo vertebrado ao qual pertencia. As contribuições de cada aluno são extremamente importantes para sua aprendizagem e socialização, mas também para identificar o quanto este aluno se envolve na atividade ou conteúdo (GOMES et al., 2016). 
Para Fialho (2007) os jogos estimulam a interação social, assim como a criatividade e favorecem o desenvolvimento do espírito competitivo. Porém, Valente (2003) afirma que a competição pode desviar os jogadores do objetivo central da proposta. Por isso é importante que o professor saliente que a função do jogo é de favorecer a aprendizagem e a interação entre os alunos (SORIANO \& BERISTAIN, 1995).

Durante algumas vezes, os jogadores retiravam do tabuleiro cartas figuras erradas ou respondiam as perguntas de maneira incorreta, porém, ao término das partidas, as equipes adversárias interagiam apontando os erros e reelaborando os conceitos previamente estudados. Os autores Moreira e Massini (2006) salientam que para que essa aprendizagem seja processada é essencial que os subsunçores sejam claros, inclusivos e que estejam, de fato, disponíveis na estrutura cognitiva do indivíduo.

Várias pesquisas têm apontado a relevância dos jogos para o processo de ensinoaprendizagem devido à possibilidade de formação de um ambiente planejado e enriquecido, concentrado no desenvolvimento de habilidades diversificadas (BOM TEMPO, 2006).

A segunda etapa da análise desse instrumento se refere à aplicação de um questionário, no qual foi realizado o levantamento de dados referente à opinião dos alunos quanto ao jogo e sua execução.

A primeira pergunta se referia ao que os alunos acharam da utilização dos jogos e se haviam gostado da atividade. Os resultados apontam um alto índice de aprovação deste recurso, conforme apresentado na figura 2.

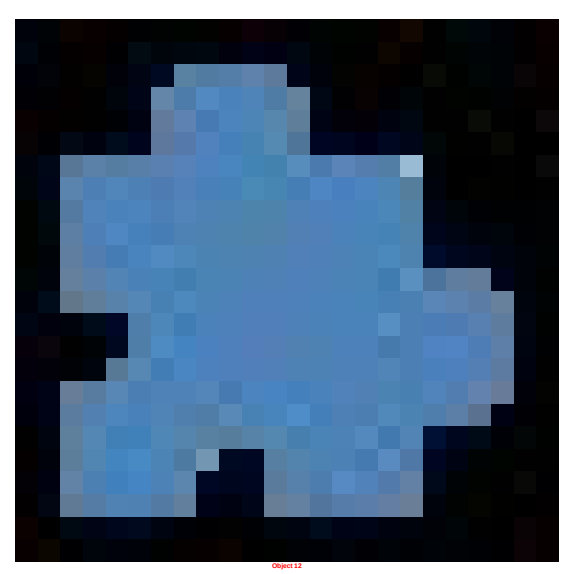

Figura 2 - Gráfico quantitativo da apreciação dos alunos pelo jogo "Qual é o bicho?". (NR se refere aos alunos que não responderam a questão).

Através destes resultados é possível perceber que a utilização desse recurso alternativo é relevante para os alunos, que majoritariamente revelaram ter gostado da atividade. Tais 
resultados corroboram com os registros apresentados por Carvalho e Chacur (2012) e Miranda et al. (2016) que apontaram a aceitação da proposta por mais de $90 \%$ dos envolvidos em ação similar.

A segunda questão é referente a opinião dos alunos quanto a elaboração das questões que foram formuladas pela equipe adversária (figura 3).

\section{Q2 - Como você classifica as perguntas do jogo?}

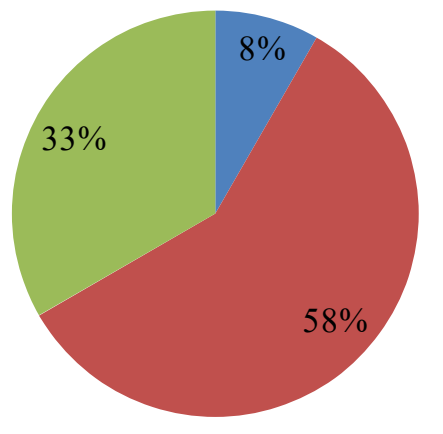

— Fáceis

— Razoáveis

Difíceis

Figura 3 - Gráfico quantitativo referente a opinião dos alunos quanto as questões elaboradas pela equipe adversária no jogo "Qual é o bicho?"

De acordo com estes resultados o percentual de alunos que definiu as questões como fáceis foi baixo em comparação aos demais critérios. Percebeu-se durante o jogo que os alunos apresentavam dificuldade em entender alguns termos científicos ou por não conhecerem alguns dos animais ilustrados no tabuleiro. Ainda assim, recorriam ao grupo para discutir e apresentar uma resposta coerente.

O presente jogo também possibilitou aos alunos um maior conhecimento dos representantes animais que compõe a fauna brasileira. Conforme Santos et al. (2010) a educação brasileira, apesar das diversas tentativas em busca da implementação de materiais para apoio didático, necessita de muita dedicação e esforço de educadores para que os recursos utilizados sejam adaptados à realidade dos alunos.

A terceira pergunta apresentada no questionário se refere a uma autoavaliação dos estudantes quanto aos conceitos explorados. Os resultados apresentados na figura 4 demonstram que metade dos envolvidos teve bom desempenho durante o jogo e $42 \%$ relataram ter desempenho razoável no que se refere a quantidade de perguntas que acertaram ou erraram após a análise das partidas, considerando promissor o desempenho geral obtido pelo instrumento de ensino. 
Q3 - Como você avalia o seu desempenho no jogo com relação aos conteúdos?

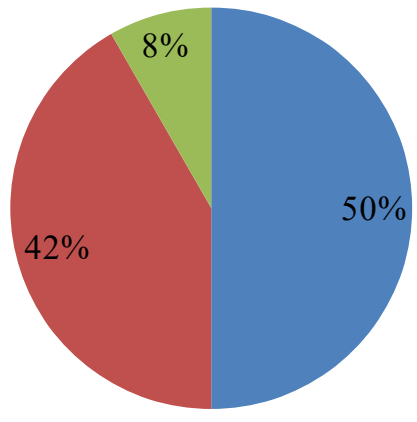

$$
\begin{aligned}
& \square \text { Bom } \\
& \text { Razoável } \\
& \text { Ruim }
\end{aligned}
$$

Figura 4 - Gráfico quantitativo representando o percentual do desempenho dos alunos quanto ao conhecimento do conteúdo do jogo "Qual é o bicho?"

O autor Ferreira (2011) destaca que a intenção do jogo não é “testar o jogador”, mas sim atraí-lo ao mundo do conhecimento. Segundo Brasil (1988) a avaliação não se restringe ao momento final do ensino, mas ao momento em que os saberes são utilizados, permitindo ao docente analisar sua prática pedagógica, o conhecimento dos alunos e os pontos a serem reelaborados, e por isso os jogos podem ser utilizados como uma ferramenta avaliativa a partir da observação sistemática, que se distancia daquilo que é tradicional: as provas alternativas ou dissertativas. $\mathrm{Na}$ opinião dos estudantes quanto ao desempenho de trabalho em equipe, os alunos deveriam refletir sobre sua participação durante as partidas e se interagiram com seus colegas para formularem perguntas ou respostas. Conforme a figura 5 os resultados foram bastante positivos, revelando que $75 \%$ dos discentes avaliaram seu desempenho como bom, onde participaram ativamente de suas equipes e $17 \%$ avaliaram como razoável.

Q4 - Como você avalia a sua participação no jogo em relação à sua equipe?

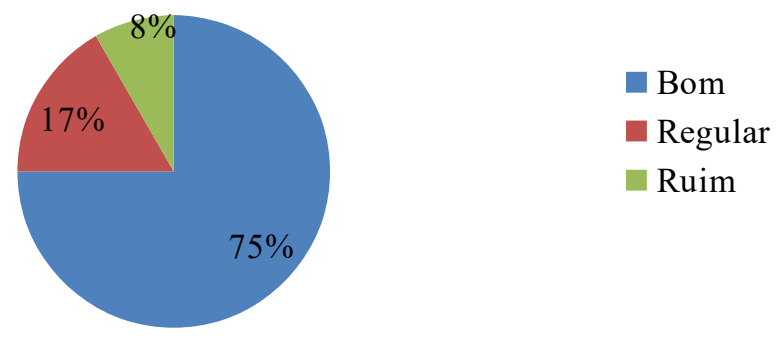

Figura 5 - Gráfico quantitativo representando o percentual da participação pessoal dos alunos quanto ao trabalho em equipe no jogo "Qual é o bicho? 
A negativa da participação de alguns alunos pode estar relacionada a dificuldade do estudante em se manifestar em público. Citações de Almeida et al. (2013) comentam que o jogo pode favorecer a desinibição do estudante, criando um ambiente descontraído, no qual ele esteja à vontade para se manifestar em público por não atribuir maiores consequências aos seus erros. Conforme relatos dos próprios alunos envolvidos na atividade, pôde-se constatar que tal prática não é realizada no presente ambiente escolar. O jogo deve merecer um espaço e um tempo maior como prática pedagógica cotidiana de ciências a ser adotada pelos professores, corroborando com Campos et. al., (2003).

O jogo tem como premissa permitir que o jogador tenha oportunidades de encontrar soluções e interagir com outros usuários, permitindo então o desenvolvimento do processo colaborativo e ampliando as estratégias coletivas de uma maneira estimulante e divertida (CARVALHO E CHACUR, 2012), desenvolvendo também a autonomia do estudante (GRANDO, 2001). Conforme enfatiza Freire (1992) esse método alternativo possibilita a vivência de novas experiências.

A última questão relata a opinião dos alunos com relação ao benefício dos jogos para a aprendizagem. Foi perguntado aos alunos, se a o jogo havia complementado o conhecimento acerca dos animais estudados. A pesquisa demonstra um resultado positivo quanto a opinião dos alunos (figura 6), sendo que 92\% indicaram que o jogo favoreceu a aprendizagem. Para Guimarães (2006) os jogos induzem a utilização do raciocínio e consequentemente a construção do conhecimento, contemplando os domínios cognitivo, psicomotor e afetivo.

\section{Q5 - O jogo te ajudou a entender mais sobre os animais estudados}

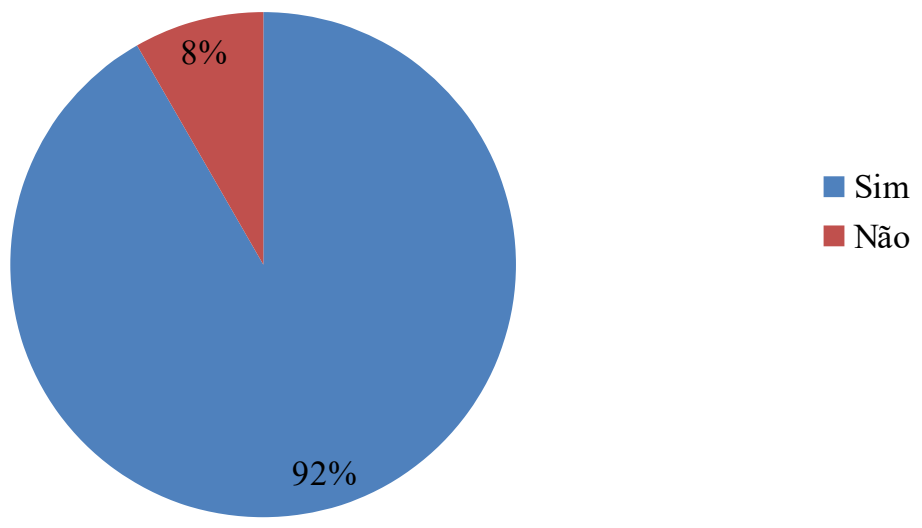

Figura 6 - Gráfico quantitativo do percentual quanto ao favorecimento da aprendizagem dos alunos por meio do jogo "Qual é o bicho?" 
De modo geral os gráficos apresentam uma mesma porcentagem de respostas $(8 \%$ dos alunos) apontando critérios insatisfatórios quanto ao jogo. Infere-se, através daanálise desses dados e a observação durante a realização da proposta, que provavelmente os mesmos estudantes tenham respondido negativamente à utilização dos jogos. Possivelmente esses discentes não tenham afinidade por este recurso didático ou pela disciplina de ciências, porém tais hipóteses não foram confirmadas.

\section{Considerações Finais}

Os jogos didáticos são considerados recursos alternativos que favorecem a aprendizagem significativa em ciências, que ocorre quando novas informações são articuladas às informações que já estão presente na estrutura cognitiva do aluno, os subsunçores. Além de favorecer o processo de ensino-aprendizagem, eles ainda possuem a função de estimular as interações e relações sociais entre seus participantes, envolvendo indiretamente o desenvolvimento de valores e atitudes.

Porém, mesmo apresentando diversos pontos positivos quanto ao desenvolvimento de habilidades variadas, os jogos são utilizados com pouca frequência pelos professores de ciências, que atualmente utilizam o método tradicional de ensino: as aulas expositivas, onde o conhecimento inquestionável é transferido sem que haja estímulo à autonomia do estudante. Neste sentido, faz-se necessário pesquisas com o objetivo de compreender os reais motivos que distanciam os professores da utilização dos jogos didáticos no ensino de ciências, visto que seus benefícios são constatados em prática.

Por fim, pode-se inferir que os jogos são instrumentos promissores durante a exploração de temas complexos na educação científica, como é o caso da área de zoologia que abrange um grande número de seres vivos morfofisiologicamente distintos. Ainda assim, é necessário que o professor saiba definir quais atividades podem alcançar de maneira mais ampla os objetivos previstos para uma aprendizagem significativa.

Agradecimentos: Ao Programa Institucional de Bolsas de Extensão PIBEX, vinculado à Próreitoria de Extensão, Cultura e Assuntos Comunitários - PROEC/UEMS pela concessão de bolsa de extensão.

\section{Referências Bibliográficas}

ALMEIDA, CMM; LOPES, Paulo Tadeu Campos; DAL-FARRA, Rossano André. O lúdico como 


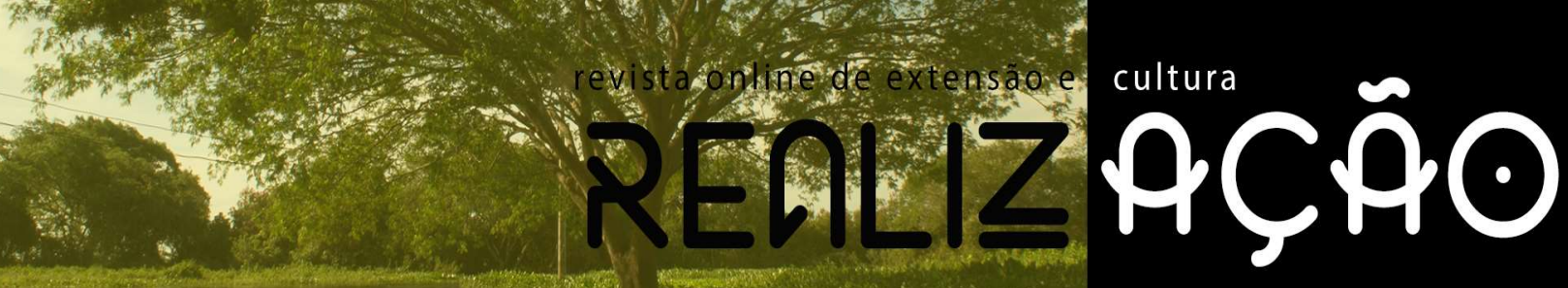

prática pedagógica no ensino de ciências: jogo didático sobre o sistema esquelético. Anais do IX ENPEC, Águas de Lindóia-SP, p. 1-12, 2013.

BRASIL. Ministério da Educação. Secretaria da Educação Fundamental. Parâmetros Curriculares Nacionais: Ciências Naturais - Brasília, 1998.

BRASIL. Orientações curriculares para o ensino médio. Volume 2, 2006. Brasília. BOMTEMPO, E. Brincar, fantasiar, criar e aprender. In: Oliveira, V.B. (Org.). O Brincar e a Criança do nascimento aos seis anos. 6 . ed. Petrópolis: Vozes, 2006.

CALVO, C. R; TEIXEIRA, R. T. S. Jogos educativos cooperativos na socialização de alunos da educação básica. PDE: Programa de Desenvolvimento Educacional. v. 1. p. 3-21. Maringá, 2014.

Campos, L. M. L., BORTOlOTO, T. M., \& FElíCIO, A. K. C. (2003). A produção de jogos didáticos para o ensino de ciências e biologia: uma proposta para favorecer a aprendizagem. Caderno dos núcleos de Ensino, 3548.

DE CARVALHO, EMERSON MACHADO; CHACUR, MÔNICA MUNGAI. Jogo Ecológico: instrumentação didática na construção de conceitos socioambientais para alunos do ensino básico. REMEA-Revista Eletrônica do Mestrado em Educação Ambiental, v. 28, 2012.Rev. eletrônica Mestr. Educ. Ambient. ISSN 1517-1256, v. 28, janeiro a junho de 2012

DOS SANTOS, Aline Borba; GUIMARÃES, Carmen Regina Parissoto. A utilização de jogos como recurso didático no ensino de zoologia. Revista electrónica de investigación en educación en ciencias, v. 5, n. 2, p. 52-57, 2010.

CUNHA, N. Brinquedo, desafio e descoberta. Rio de Janeiro: FAE, 1988.

CANDIDO, C; FERREIRA, J.F. Desenvolvimento de material didático na forma de um jogo para trabalhar com zoologia dos invertebrados em sala de aula. Cadernos da Pedagogia. São Carlos, Ano 6, v.6, n.11, p.22-33, jul-dez, 2012.

FERREIRA, J. M. et al. Elaboração de jogos didáticos no PIBID em dupla perspectiva: formação docente e ensino de Física. Anais do VIII ENPEC. P.1-12. 2011. Disponível em: http://www.nutes.ufrj.br/abrapec/viiienpec/resumos/R0624-2.pdf. Acesso: 30 mar. 2013.FIALHO, N.N. Jogos no ensino de Química e Biologia. Curitiba: IBPEX, 2007.

FORTUNA, T. R. Jogo em aula: recurso permite repensar as relações de ensino aprendizagem. In: Revista do Professor, Porto Alegre, v .19, n.75, p.15-19, Jul./Set. 2003.

FREIRE, P. Pedagogia da Esperança: um reencontro com a pedagogia do oprimido. Rio de Janeiro: Paz e Terra, 1992.

GRANDO, R, C. O jogo na educação: aspectos didáticos metodológicos do jogo na educação matemática. Unicamp, Campinas, 2001.

GOMES, Carla Ribeiro de Paiva; SILVA, Fábio Augusto Rodrigues. O “Mistério no Zoo”: um jogo 
para o ensino de zoologia de vertebrados no ensino fundamental II. Revista da SBEnBio - Número 9 - 2016 GUIMARÃES, O. M. Caderno Pedagógico: Atividades Lúdicas no Ensino de Química e a Formação de Professores. Projeto prodocência . MEC/SESU- DEPEM, UFPR. 2006.

HUIZINGA, J. Homo ludus. 4 ed. São Paulo: Perspectiva, 2000.

HUIZINGA, J. Homo ludens: O Jogo como elemento da Cultura. São Paulo: Perspectiva. 1971.

KISHIMOTO, T. M. O jogo, a criança e a educação. 12 ed. Petrópolis, RJ: Vozes, 2004.

KRASILCHIK, Myriam. Prática do ensino de biologia. $4^{\mathrm{a}}$ ed. São Paulo: Editora da Universidade de São Paulo, 2011.

SILVA, A, M, T, B; METRAU, M, B; BARRETO, M, S, L. O lúdico no processo ensinoaprendizagem das ciências. Revista Brasileira de Estudos Pedagógicos-RBEP, Brasília, v. 88, n. 220, p. 445-448, set./dez. 2007. Disponível em: $<$ http://rbep.inep.gov.br/index.php/rbep/article/view/733/709>. Acesso em: 22 nov. 2015.

MIRANDA, J.C.; GONZAGA, G.R.; COSTA, R.C. Produção e avaliação do jogo didático "tapa zoo" como ferramenta para o estudo de zoologia por alunos do ensino fundamental regular. Holos - v.4, pp. 383-400, 2016.

MOREIRA, Marco Antônio. Teorias de Aprendizagem. São Paulo: EPU, 2014.

MOREIRA, M. A. \& MASINI, E. F. S. Aprendizagem Significativa: A Teoria de David Ausubel. São Paulo/SP: Ed. Centauro, 2006.

ORLICK, T. Vencendo a Competição. São Paulo: Círculo do Livro, 1989.

PIAGET, J. O Nascimento da Inteligência na Criança. Rio de Janeiro: Zahar, 1982.

SCHNETZLER, R. P. Construção do conhecimento e ensino de Ciências. Em Aberto, 1992.

SORIANO, P.C.; BERISTAIN, C.M. La alternativa del juego I: jueogs y dinámica de educación para la paz. Madri: Los Libros de la Catarata, 1995. 254p.

VALADARES, J. A teoria da aprendizagem significativa como teoria construtivista. Aprendizagem Significativa em Revista/Meaningful Learning Review - v1(1), pp. 36-57, 2011.

VALENTE, J.A. Diferentes usos do computador na educação. 1993. Disponível em: http://www.educacaopublica.rj.gov.br/biblioteca/tecnologia/0022.html. Acesso em: 05 de Abril de 2018. 